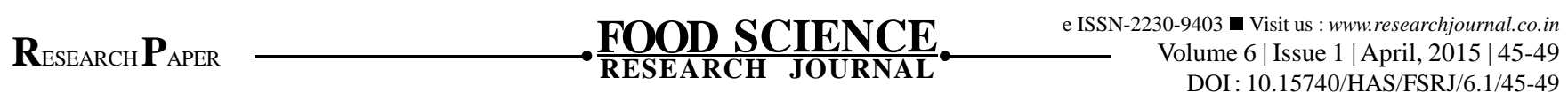

\title{
Novel products from cashew apple - Jelly and cake
}

\author{
A. Sobhana and Jose Mathew
}

Cashew apple is a pseudo fruit formed by the swollen receptacle. It is highly nutritious and is a valuable source of sugar, minerals and vitamins. Ripe apple is very juicy and spongy having a unique flavour and smell. The astringent and acid principles in cashew apple produce a rough unpleasant and biting sensation on the tongue and throat, major draw back of the fruit which prevents the consumption of fresh fruits. Hence, the removal of astringency is the primary step in cashew apple processing. Technologies have been standardized for the detanning of cashew apple and clarification of juice as well as for the preparation of many value added products from cashew apple at Cashew Research Station, Madakkathara under Kerala Agricultural University. As a part of the preparation of novel products, a trial was carried out for standardizing the technology for the production of jelly and cake from cashew apple at Cashew Research Station, Madakkathara. Fresh apples collected from the field were washed well and cashew apple extract was prepared by boiling $250 \mathrm{~g}$ cashew apple pieces in $500 \mathrm{ml}$ water for 30 minutes. Jelly was prepared using the cashew apple extract, sugar, gelatin, guava fruit extract and china grass along with pineapple, mango pulp, ginger drops and cardamom powder in different combinations. Sensory scoring of the samples revealed that the sample prepared with cashew apple extract, sugar, gelatin and cardamom powder showed maximum acceptability and the exact consistency of jelly. In another trial, different types of cakes were tried from cashew apple powder. Cashew apples collected from the field were washed and detanned using common salt @ 5\% and made into small pieces, then dried and powdered. This powder was used for making cake after mixing with sugar, maida, egg, butter, milk, baking powder etc in different combinations. The sample prepared by using $30 \mathrm{~g}$ maida, $20 \mathrm{~g}$ cashew apple powder, $75 \mathrm{~g}$ butter, $200 \mathrm{~g}$ condensed milk and a pinch of baking powder showed maximum acceptability in the organoleptic scoring of the samples.

Key Words : Cashew apple, Astringency, Detanning, Consistency

How to cite this article : Sobhana, A. and Mathew, Jose (2015). Novel products from cashew apple - Jelly and cake. Food Sci. Res. J., 6(1): 45-49. 